\title{
DEVELOPMENT OF SHRINKAGE RESISTANT CEMENT-BASED MATERIALS USING FIBERS
}

\author{
PEDRAM HAMEDANIMOJARRAD, GEORGIUS ADAM, ABHI S. RAY, KIRK VESSALAS \\ and PAUL S. THOMAS \\ Centre for Built Infrastructure Research, Faculty of Engineering, University of Technology, \\ Sydney, Australia.
}

\begin{abstract}
Drying shrinkage is the major contributor to volume changes in normal strength concrete. Several classes of shrinkage compensating admixtures are known to the concrete industry. This study deals with the literature review and categorization of different classes of shrinkage reducing fibers, especially polyethylene fibers, with the objective of introducing new types of shrinkage reducing fiber. In this investigation a special type of hydrophobic polyethylene minifibers has been used in different dosages in mortar samples. The experimental results on drying shrinkage as well as on several other properties are reported. The hydrophobic minifibers showed remarkable improvement in shrinkage reduction even at very low concentrations ( $0.1 \%$ of cement weight).
\end{abstract}

Keywords: Drying shrinkage, mortar, minifiber, hydrophobic, expansive admixture.

\section{Introduction}

Cement-based materials including mortar and concrete are subject to different types of volume changes in their service life. Once mortar and concrete have been exposed to dry conditions, the material begins to lose water and then shrink. The loss of free water from large cavities present in paste microstructure may not result in shrinkage; however the loss of adsorbed water and water held in small capillary pores result in a reduction in disjoining pressure, which is known as the principal cause of drying shrinkage (Mehta 2006).

The formation of cracks in cement-based materials is due to tensile stress or different forms of shrinkage when the specimen is restrained. Once the cement-based material cracks, chemicals can enter and diffuse through the cementing matrix. In order to prevent cracking of concrete, fibers may be incorporated into the mix to provide reinforcement. Fibers are expected to be discontinuous, and randomly distributed throughout the cement paste matrix, and in consequence they act well in crack controlling (Bentur and Mindess 2007).

\section{Fibers in Shrinkage Reduction}

Fibers are commonly accepted for their immediate effects in shrinkage cracking resistance, rather than shrinkage reduction.

To date, there have been several types of fibers introduced to the construction industry. Bentur and Mindess (2007) have listed them as steel fibers, glass fibers, natural fibers and other synthetic fibers which include polypropylene, polyethylene, acrylic, polyester, nylon, carbon, Aramid and PVA.

Pelisser et al. (2010), stated that the addition of short polypropylene fibers to the mortar mix was efficient in preventing considerably crack formation due to plastic shrinkage. Sivakumar et al. (2007) stated that in hybrid fiber combinations, the steelpolyester combination led to a significant reduction in cracking, compared to plain concrete. Mesbah et al. (1999) reported that cast iron fibers are more efficient than polypropylene fibers in reducing cracking, although the use of both types contribute to delaying the overall development of cracks. Kayali et al. (1999) reported higher drying shrinkage strain for lightweight aggregate 
concretes reinforced with polypropylene or steel fibers, compared to plain concrete.

Vegetable fiber reinforced composites have also been studied. Toledo et al. (2005) carried out shrinkage measurement tests and stated that free plastic shrinkage can be reduced by the inclusion of $25 \mathrm{~mm}$ short sisal fibers in cement mortar. These authors also reported that addition of $25 \mathrm{~mm}$ sisal and coconut fibers can delay the initial cracking for restrained plastic shrinkage and effectively controls crack development at the early age of composite. Soroushian and Ravanbakhsh (1998) have also employed cellulose fibers and found $78 \%$ reduction in plastic shrinkage crack area relative to plain conventional concrete. Boghossian and Wegner (2008) studied the influence of flax fibers and showed that the total projected area of cracks forming on the surface of specimens within the first $24 \mathrm{~h}$ was reduced by more than $95 \%$ relative to plain mortar specimens, and maximum crack widths were reduced by more than $90 \%$ to less than $0.18 \mathrm{~mm}$.

Chen and Chung (1996) indicated that the use of $0.19 \%$ by volume short carbon fibers $(0.5 \%$ of the cement weight) in silica fume modified concrete resulted in $84 \%$ decrease in drying shrinkage strain after 14 days storage in air.

Passuello et al. (2009) reported that addition of fibers does not greatly modify the cracking time, but does reduce the crack width by about $70 \%$ in the case of long fibers, and by almost $90 \%$ with short fibers.

\subsection{Polyethylene fibers}

High modulus fibers usually show high ultimate strength, low strain capacity and small crack width properties, while low modulus fibers have low ultimate strength, high strain capacity and large crack width properties (Ahmed et al. 2007). Polyethylene can be categorized as low modulus synthetic fiber. However it can be produced with a relative high density.

In related studies, two different geometry of polyethylene fibers have been used in cement-based specimens: (1) short and dispersed, up to $4 \%$ by volume; (2) continuous network of fibrillated fibers and about $10 \%$ by volume of concrete sample (Bentur and Mindess 2007).

Regarding structural studies, Ahmed and Maalej (2009) stated that the ultimate tensile strain capacity was found to increase with increase in polyethylene fiber contents and beyond a particular fiber content the strain capacity decreased. Kobayashi and Cho (1981) confirmed that the characteristic feature of polyethylene fiber reinforced concrete as a structural material, might be its excellent ductility. Soroushian et al. (1993) illustrated that both polyethylene pulp and fiber tended to increase the impact resistance, flexural strength and toughness of cementitious materials. They also experienced positive effects on the compressive strength of cement-based matrices.

\section{Significance}

In this study a new type of polyethylene fibers is examined to study the drying shrinkage characteristics of fiber reinforced mixes. This synthetic fiber is hydrophobic monofilament polyethylene minifiber of $0.1 \mathrm{~mm}$ length, 5 micrometer diameter and surface area of $12 \mathrm{~m}^{2} /$ gr. This especially cut short fiber is available for different application.

Hydrophobic polyethylene minifibers are expected to reduce the amount of moisture loss in samples due to blockage of capillary pores inside cement paste matrix, while they are dispersed in the paste and repel water. Using minifiber as an additive, laboratory experiments were fulfilled using different dosages of that to evaluate its efficiency as anti-shrinkage additive and its effect on the physical and mechanical characteristics of mortar specimens.

Since mortar samples are more vulnerable to dry shrinkage than concrete samples with the same size and shape, they have been used in this research project.

\section{Experimental Investigation}

Australian standards (AS) have been followed for these sets of experiments. The 
prismatic test specimens were $40 \times 40 \times$ $145 \mathrm{~mm}^{3}$ insize(Standards-Australia2006b).

For the first 20-24 hours after mixing, all the specimens were kept in a moist environment where the relative humidity was more than 95\% (Standards-Australia 2006a). After demoulding, all the specimens were initially measured for their length and maintained inside the humidity-controlled cabinet at a temperature of $23 \pm 1{ }^{\circ} \mathrm{C}$ and a relative humidity of not less than $50 \%$ (StandardsAustralia 2006b).

\subsection{Material, mortar mix proportions}

General Purpose Cement from CementAustralia was used. Raymond Terrace single washed sand (Rocla Quarry Products) was the aggregate used in laboratory tests. Additionally, a polycarboxylate Ether polymer based, high-range water reducing admixture, supplied by BASF Construction Chemicals was used as superplasticiser to adjust workability. For comparing purposes, all mixes consist of same concentration of superplasticiser.

All the tests were carried out at $22 \pm 1^{\circ} \mathrm{C}$. In order to obtain comparable results for the evaluation of the new additive, as a set of test, about 4 different mixes, including control mix, were carried out on the same day and under the same environmental ambient. Mortar mix designs, presented in Table 1 were derived and modified from standardized proportions listed under AS2350.12 (2006a). Preparation of mortar mixes were carried out in accordance with the same code.

The shrinkage reducing additive was first added to cement, and the whole bag

Table 1. Mix proportions of mortar specimens.

\begin{tabular}{lccccc}
\hline $\begin{array}{l}\text { Mixes Raw } \\
\text { materials }\end{array}$ & Co & Fi0.01 & Fi0.05 & Fi0.1 & Fi0.3 \\
\hline Cement (g) & 450 & 450 & 450 & 450 & 450 \\
Sand (g) & 1350 & 1350 & 1350 & 1350 & 1350 \\
Water(g) & 224.4 & 224.4 & 224.4 & 224.4 & 224.4 \\
Superpl. (ml) & 1 & 1 & 1 & 1 & 1 \\
Fiber(g) & 0 & 0.045 & 0.225 & 0.45 & 1.35 \\
\hline
\end{tabular}

was very well vibrated in order to have a consistent mixture of cement and additive.

In Table 1, the term "Co" stands for the control mix without any fiber. Terms Fi $0.01 \%$ to $\mathrm{Fi} 0.3 \%$ stand for mixes with polyethylene fibers concentration of $0.01 \%$ to $0.3 \%$ to cement mass, respectively.

\subsection{Shrinkage measurement}

Immediately after demoulding, all the specimens were subject to initial length measurement to the nearest $0.001 \mathrm{~mm}$, using drying length comparator. Subsequent measurements were also taken at the ages of 7, 14, 21 and 28 days after casting. The drying shrinkage for $7,14,21$ and 28 days was calculated by $\Delta L / L$ (Neville 1995, Standards-Australia 2006b), Where $\Delta L$ is the difference between the initial length measurement taken immediately after demoulding and the length reading at the particular age, and $L$ is the original length of the sample.

\subsection{Physical properties}

Physical properties of mixes including the flow, mass changes of specimens during 28day ambient storage and 28-day compressive strength are also studied.

Mixing and casting of mixes with $1.0 \%$ or more concentration of minifiber was too difficult, since the produced mix was not workable enough for mixing and casting. They could be made workable by adding more superplasticiser, but for omitting the possibility of superplasticiser effects on drying shrinkage for comparing purposes, the results of mixes with $1 \%$ or more of minifiber are not reported in this paper.

\section{Results}

\subsection{Fresh properties}

Figure 1, shows the flow of mortars based on measurements carried out in accordance with ASTM standards (ASTM 2007). A reduction in workability was observed with increasing additions of minifibers to the mortar mixes. Since the density of minifibers is low (approximately 0.96), adding more 


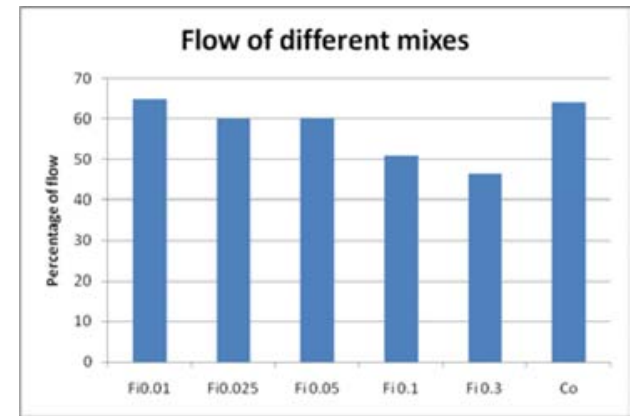

Fig. 1. Flow properties of different mixes.

amounts to the mortars could increase the proportion of dry raw materials used in the mix.

\subsection{Hardened properties}

\subsubsection{Drying shrinkage}

The results of drying shrinkage in first 28 days air storage of mortar specimens are shown in Figures 2 and 3. From these figures, drying shrinkage is found to reduce with addition of minifiber. Of most significance, there was a reduction of $18 \%$ shrinkage observed after 28 days for the Fi0.1\% mix. Considering the improvements observed in reducing shrinkage, lower concentrations of minifiber additions were considered; however, no further improvements in drying shrinkage reduction were observed (Figure 3).

It is likely that the $0.1 \%$ addition of minifiber acts as an optimum addition amount for shrinkage reduction.

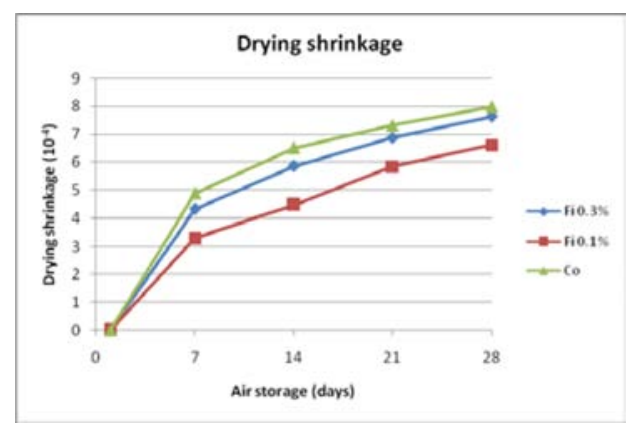

Fig. 2. Drying shrinkage of mixes.

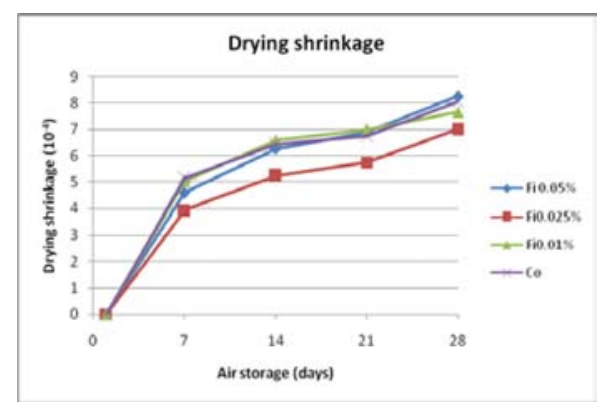

Fig. 3. Drying shrinkage of mixes.

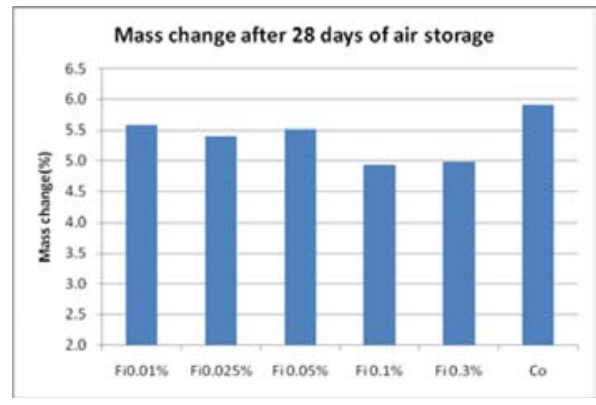

Fig. 4. Mass changes of mixes.

The mass of each sample was also measured during each subsequent length measurement. Results of \% mass change are shown in Figure 4. From this figure, the \% mass change was found to be lower for all additions of minifibers than for the Co mix. The Fi0.1\% mix demonstrated the lowest \% water loss.

\subsubsection{Compressive strength}

Specimens with minifibers were found to have lower compressive strength when

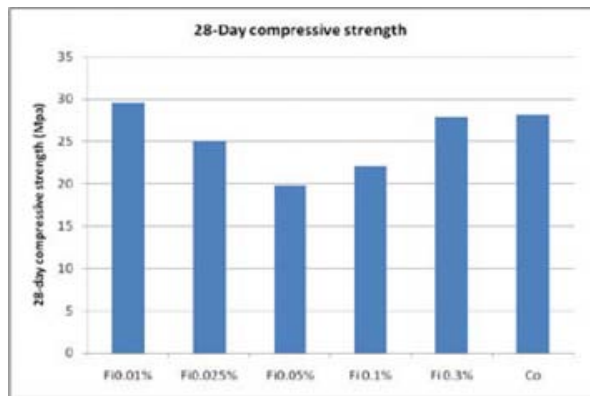

Fig. 5. 28-day compressive strength of mixes. 
compared to control mix. Figure 5 depicts the 28-day compressive strength results for all mortar specimens.

Compressive strength of mortars incorporating low addition amounts of minifibers, such as $0.01 \%$ was comparable to the Co mix. But with increasing minifiber additions the compressive strength was found to decrease with a tangible trend.

\section{Discussion}

Adding a low dosage of polyethylene minifibers has demonstrated that drying shrinkage of mortar specimens can be reduced. However, different results were obtained for different concentration amounts of minifibers. In addition, a direct relationship between shrinkage reduction and specimen water loss was observed for each mix. That is, less drying shrinkage was found with lower moisture loss.

In addition, the measurements of wet densities performed in accordance with ASTM (ASTM 2009), indicate that adding minifibers to mortar increases the wet density compared to control mortar. Polyethylene minifibers resulted in a reduction of 28-day compressive strength which may be due to adding non reacting fibers.

The mechanism proposed for shrinkage reduction using minifibers may be interrupting the capillary structure formation in the mortar due to the presence of hydrophobic fibers in the cement paste, which results in decreasing the water transfer from the inner layers of matrix to the surface. Figure 4 proves this mechanism, since the changes in mass of mixes with minifibers are less than those of the control samples.

\section{Conclusions}

An optimum amount of $0.1 \%$ of polyethylene minifibers was found to significantly reduce drying shrinkage.

Since the addition of minifibers reduced compressive strength, changing the mix proportions is proposed. Water repellent which was the expected, was the mechanism involved in shrinkage reduction.

\section{References}

Ahmed, S. F. U. and Maalej, M., Tensile Strain Hardening Behaviour of Hybrid Steel-Polyethylene Fibre Reinforced Cementitious Composites, Construction and Building Materials, 23, 96-106, 2009.

Ahmed, S. F. U., Maalej, M. and Paramasivam, P., Flexural Responses of Hybrid Steel-Polyethylene Fiber Reinforced Cement Composites Containing High Volume Fly Ash, Construction and Building Materials, 21, 1088-1097, 2007.

ASTM, Standard Test Method for Flow of Hydraulic Cement Mortar, C1437, ASTM International, 2007.

ASTM, Standard Test Method for Density (Unit Weight), Yield, and Air Content (Gravimetric) of Concrete, C138/C138M, ASTM International, 2009.

Bentur, A. and Mindess, S., Fibre Reinforced Cementitious Composites, Taylor \& Francis, 2007.

Boghossian, E. and Wegner, L. D.,Use of Flax Fibres to Reduce Plastic Shrinkage Cracking in Concrete, Cement and Concrete Composites, 30,929-937, 2008.

Chen, P. W. and Chung, D. D. L., Low-DryingShrinkage Concrete Containing Carbon Fibers, Composites Part B: Engineering, 27, 269-274, 1996.

Kayali, O., Haque, M. N. and Zhu, B., Drying Shrinkage of Fibre-Reinforced Lightweight Aggregate ConcreteContaining Fly Ash, Cement and Concrete Research, 29, 1835-1840, 1999.

Kobayashi, K. and Cho, R., Flexural Behaviour of Polyethylene Fibre Reinforced Concrete, International Journal of Cement Composites and Lightweight Concrete, 3, 19-25, 1981.

Mehta, P. K. and M., M. P. J., Concrete Microstructure, Properties, and Materials, McGraw-Hill Companies, Inc, 2006.

Mesbah, H. A. and Buyle-Bodin, F., Efficiency of Polypropylene and Metallic Fibres on Control of Shrinkage and Cracking of Recycled Aggregate Mortars, Construction and Building Materials, 13, 439-447, 1999.

Neville, A. M., Properties of Concrete, Longman Group Limited, 1995.

Passuello, A., Moriconi, G. and Shah, S. P., Cracking Behavior of Concrete with Shrinkage Reducing Admixtures and PVA Fibers, Cement and Concrete Composites, 31, 699-704, 2009.

Pelisser, F., Neto, A. B. D. S. S., Rovere, H. L. L. and Pinto, R. C. D. A., Effect of the Addition of Synthetic Fibers to Concrete Thin Slabs on Plastic Shrinkage Cracking, Construction and Building Materials, In Press, Corrected Proof, 2010.

Sivakumar, A. and Santhanam, M., A Quantitative Study on the Plastic Shrinkage Cracking in High Strength Hybrid Fibre Reinforced Concrete, Cement and Concrete Composites, 29, 575-581, 2007. 
Soroushian, P. and Ravanbakhsh, S., Control of Plastic Shrinkage Cracking with Specialty Cellulose Fibres, ACI Materials Journal, 95, 17, 1998.

Soroushian, P., Tlili, A., Alhozaimy, A. and Khan, A., Development and Characterization of Hybrid Polyethylene-Fibre-Reinforced Cement Composites, Construction and Building Materials, 7, 221-229, 1993.

Standards-Australia, Methods of Testing Portland, Blended and Masonry Cements Method 12: Preparation of a Standard Mortar and Moulding of Specimens, AS2350.12, Standards Australia, 2006a.

Standards-Australia, Methods of Testing Portland, Blended and Masonry Cements Method 13: Determination of Drying Shrinkage of Cement Mortars, AS2350.13, Standards Australia Limited, 2006b.

Toledo Filho, R. D., Ghavami, K., Sanjuán, M. A. and England, G. L., Free, Restrained and Drying Shrinkage of Cement Mortar Composites Reinforced with Vegetable Fibres, Cement and Concrete Composites, 27, 537-546, 2005. 